\title{
Impact of Ethical Behavior on Financial Performance of Firms Listed on Ghana Stock Exchange.
}

\author{
Obeng Kwakye $^{1} \quad$ Kong Yusheng ${ }^{1} \quad$ Emmanuel Baffour Gyau ${ }^{2 *}$ \\ 1. School of Finance and Economics, Jiangsu University, 301 Xuefu Road, Jingkou Qu Zhenjiang, Jiangsu \\ Province, China. \\ 2. Institute of Science and Technology Information, Jiangsu University, 301 Xuefu Road, Jingkou Qu \\ Zhenjiang, Jiangsu Province, China. \\ * E-mail of the corresponding author: papagyau24@gmail.com
}

\begin{abstract}
The focus of this study was to assess the effect of organizational ethical behavior on the financial performance of firms in Ghana. Researchers have expressed concerns about the ethical behavior of firms in Ghana with regards to its effect on financial performance. The findings of this study will add to the literature, from which those in the field of academia can continually refer. The return on assets, as an indicator for the financial performance of firms, was adopted as the dependent variable. Independent variables were good ethical behavior (GEB), corruption reduction $(\mathrm{C})$, and nepotism reduction $(\mathrm{N})$. A cross-sectional survey design was followed for primary data and firms' financial records were sources of secondary data. Thirty (30) corporate firms registered on the stock market were selected for the study.

A multiple regression analysis was conducted and findings presented in Tables and Figures. Results showed that firms' adherence to ethical principles of conducting business stand the chance of increasing their financial performance up to $45.0,38.4$, and $43.7 \%$ by unit increases in GEB, and decreases in $\mathrm{C}$, and $\mathrm{N}$ respectively. All independent variables had positive correlations with the financial performance of firms studied (GEB, 0.349; C, $0.503 ; \mathrm{N},-0.680$ ). On firms' financial performance, the ROA of firms, according to findings is positively and strongly correlated to their adherence to ethical business standards.

Based on these findings, the study recommends that corporate firms pay more attention to practices that enhance good ethical behavior through the implementation of ethics policies, and reduce or eradicate nepotism to increase their chances of performing better financially. In addition, firms should ensure gender equality and equity, employee training on ethical standards of work, and encouragement of ethical leadership.
\end{abstract}

Keywords: Ethical behavior, Financial Performance, Organization, Listed companies.

DOI: $10.7176 / \mathrm{EJBM} / 13-14-10$

Publication date:July $31^{\text {st }} 2021$

\section{Introduction}

According to earlier scholars, the definition of behavior is characterized by the fact that it is a function of both the persons and the environment (Lewin 1951). Ethical behavior is generally an acceptable way of doing things and the opposite describes unethical behavior. In earlier works, the exhibition of unethical behavior by employees of any organization has been shown to have the ability to influence individuals, workgroups, as well as an entire organization in terms of its overall performance (Beck and Andrews 1989). This subject area has become crucial to many businesses in recent times and several research works are focusing on understanding the relationships between ethical behavior and organizational performance (Pučètaitè 2014, Lau, Tong et al. 2017, Naiyananont and Smuthranond 2017, Dimitriou and Ducette 2018, Kim, Kim et al. 2019). Based on the fact that individuals make up an organization and the fact that individual actions have multiplying effects, more and more organizations are depending on individual employees and expecting them to act according to set standards of behavior (Wagel 1987, Naiyananont and Smuthranond 2017, Kim, Kim et al. 2019).

Modern organizations are constantly seeking ways of gaining a competitive advantage in business. One sure way of remaining relevant in business is ensuring that the organization has a vibrant business culture and a good corporate image. The culture of an organization provides standardized conduct employees are expected to exhibit to achieve the goals of the organization and through this, it acquires its corporate identity. Focus on the culture of 
the organization thus enables managers and subordinates to understand the approved standards of behavior which underpin the day-to-day interactions that would enhance productivity within the workplace environment. This viewpoint is underscored by Asare-Bediako a Ghanaian Human Resource management and organization development consultant who has stated that: -Most managers believe that strong organizational culture, closely linked to organizational objectives and goals, can mean the difference between success and failure in today's business world (Asare-Bediako 2002). This assertion suggests that a close correlation exists between what employees do or do not do to achieve the set goals - corporate culture - and organizational efficiency and success - good corporate image. Establishing the appropriate framework for organizational culture requires that the elements and principles must go through consultations and a formal approval process to ensure general acceptability and applicability to meet the expected standards of attitudes and conduct required within the organization (Asare-Bediako, 2002).

Amos (2012), said that "societal ethics provide the basis on which a civilized state exists", and that "without these ethics, civilization collapses". This same concept works for the link between business ethics and business organizations- in that, ethical behavior peculiar to a particular business influences the performance of that business (Lau, Tong et al. 2017). According to Amos (2012), ethics provide the basis for the development of organizational culture and structure. By definition, ethics can be said to comprise of values and principles that govern the way a person acts, or a group of people behaves in the light of right and wrong (Levine and Boaks 2014, Kim, Kim et al. 2019). Thus, ethics cut across all fields and is described by a complex relationship between the principles of state laws, personal beliefs, religious beliefs, morals, social norms, and values, and is dependent on the features of particular cultures. On the other hand, the ethics of business is the set of acceptable behavior that a business adheres to in its daily operations and interactions with people in a global context (Enofe, Omagbon et al. 2015). According to Amos (2012), business ethics do not only apply to how the business interacts with the world at large, but also to their dealings with customers regarding their satisfaction with products and services, including human relational experiences (Levine and Boaks 2014).

Every organization in the world has one main goal, which is to grow based on positive performance and sustainability (Kim, Kim et al. 2019). The recruitment and allocation of resources are based on strategies that align to organizational goals are largely dependent on the works and competence of individual employees and their behavior towards jobs or tasks assigned them (Onyema 2014). The growth of a business organization relies heavily on its ability to develop, implement and enforce strict adherence to a sound ethical code of conduct set to guide both management and employee towards organizational goal achievement in a strategic manner (Koc and Çavuş 2014, Lau, Tong et al. 2017).

Some scholars have mentioned that organizations encounter many ethical dilemmas at varying levels of significance in their daily business activities and that there is a high conflict between ethics and business activities (Cohen 2010, Sennewald and Baillie 2016). Certain individuals and businesses are faced with challenges and the temptation to indulge in unethical behaviors especially when not intended to be a habitual practice, where there is a rare opportunity to grasp out of the blue. Such behaviors most often than not work in the favor of those individuals and organizations but at the expense of other individuals, organizations, and even the environment and society at large. Certain times also, the effects are long-lasting such that generations come to suffer consequences over long periods. It can be confidently argued that organizations adhere more to the ethics of their businesses when such behaviors are meant to enhance their benefits, and in instances where adherence may cost them, they are more likely to bend the rules in favor of their gains in the long run (Sennewald and Baillie 2016).

The lack of practicing ethics and behaving according to ethical policies can reduce the performance of an organization. This lack may cause incongruities, litigations, dissatisfaction of customers, loss of customer loyalty, poor delivery of service, poor time management, bribery, and corruption among many others that cannot be mentioned here (Alem, Eggert et al. 2018, Zhao, Zhou et al. 2019). Lots of behavior of staff of organizations can be classified as unethical such arrogance, sexual harassment, fights, ignorance, neglect, absenteeism, alcohol consumption, smoking, and neglect and these have negative effects on organizational performance (Alem, Eggert et al. 2018, Seuntjens, Zeelenberg et al. 2019). As known, the culture of every organization is unique to the core values of the organization and the ability of an organization to develop and implement an ethical behavior policy that transcends usual duties and which binds on all staff can be a source of breakthrough and one that is of competitive advantage and difficult to be imitated by other organizations. 


\section{Literature review}

Amid many definitions, ethical behavior is described by the ways an individual acts that are in synchrony with the values, beliefs, morals, regulations, as well as other commonly held values of groups, organizations, and society. Several studies have focused on this subject, especially in studying its effects on organizational performance and employee job satisfaction among many others (Kumari and Pandey 2011, Valentine and Bateman 2011). Unethical behavior by employees can affect individuals, work teams, and even the organization (Kim, Kim et al. 2019). Organizations thus depend on individuals to act ethically. An organization's ability to elicit ethical behavior that goes above and beyond the call of duty can be a key asset and one that is difficult for competitors to imitate. "It's not enough to just show up at 8 o'clock each morning and say, "oh, I have done a wonderful thing" (Turnley, Bolino et al. 2003). Corporate growth is enhanced with ethical policies that are aligned with organizational culture, core values, mission, and vision and which serve as constant reminders of organizational goals ( $\mathrm{Ng}$ and Feldman 2015). Ethical behavior in organizations is necessary because businesses can become unethical, and there is plenty of evidence on unethical organizational practices (Kumari and Pandey 2011). Irrespective of the demands and pressures faced by organizations, the fact that it exists is enough reason that it conducts itself in an ethically acceptable manner. In this respect, the theory alerts us about the influences which sub-cultures can have on an organization either "positively as a facilitator of effectiveness and success or negatively as a barrier to morale, motivation, and performance". (Asare-Bediako 2002).

Business Ethics of organizations are largely influenced by the existing political and socio-cultural environment, and Ghanaian firms are no exception. In this regard, the book" Business Management" published by the Institute of Chartered Accountants Ghana (ICAG 2009), has identified ten common socio-cultural elements of the Ghanaian social environment which may influence the ethical orientations of employees, managers, and leaders within Ghanaian organizations. They include: "Belief in the benevolence of the creator; extended family system; respect for elders; stress on achievement; authoritarian political structure; hospitality and gratitude; maledominated society and a show of masculinity; society dominated by communal values; and a similar attitude to time". (ICAG 2009).

For listed firms in Ghana, the debate is whether the country has moral leaders whose reasoning can be depended on to provide ethical leadership. Human Resource (HR) is most likely to adopt an employee development method to ethics training. The Cognitive Moral Development Theory proposes that moral judgment can be enhanced with explicit training processes designed to challenge the thinking of individuals by establishing cognitive conflict (Gibbs 2019). From the theory, what people believe, think, and feel affects how they behave (Bandura 1986). With the function of culture creation and management falling under HR policies, the affected leaders need to create and manage an ethical cultural environment (Schein 2010). Managers should thus create enabling environments that seek to encourage and mentor employees. Employees who are most likely to find themselves needing to make autonomous decisions in ethically abstruse situations (e.g., during overseas assignments) could likely profit from similar training methods. Organizational policies should be well defined both in the organizational and psychological climates (Jensen 2010). To promote a values-oriented and integrated ethics program, organizations should incorporate concerns for ethics and fairness in the appraisal processes.

The top-level management of the Civil Service (the implementers) must redouble their efforts to understand, accept and commit themselves fully to the guiding principles of public life under the Code of Conduct which includes Selflessness, Integrity, Justice and Fairness, Accountability, Transparency, and Leadership; As well as the key elements of the Work Ethics which, are punctuality, devotion to duty, guarding against absenteeism, obedience to lawful instructions, taking pride in and joy of duty, customer satisfaction with urgency, timely performance of duty and achieving goals of the organization must translate into visible and sustainable conduct throughout the entire organization. There is also the need to commit themselves fully to acquiring these professional ethics as the bedrock for efficiency, effectiveness, loyalty to an organization, and the display of market-orientated work ethics and conduct for achieving results-oriented work output.

The current performance of firms is the first to be evaluated by investors around the world. At present, the world has become smaller and the opportunity to do business anywhere in the world. Globalization has contributed to the high performance of enterprises because economic globalization has helped people all over the world. Development and growth are achieved by removing barriers to commercial trade and financial investment, and better opportunities can be opened up. Performance measurement is critical to the effective management of an organization, and process improvement is not possible without the measurement of results. Therefore, organizational performance requires taking steps to determine the impact of organizational resources on business performance. 
Theoretically, this research found that accounting-based indicators such as ROA, ROE, profit margin, and other indicators were used to evaluate the company's short-term business results, while the company's market indicators were evaluated using Tobin Q criteria as indicators of future long-term performance. Thus, the integration between them gives a clear picture of the company. Despite the widespread use of measurements, the results are still inconclusive. While some companies found a positive relationship between corporate governance and firm performance through accounting and market-based measurement, others revealed a negative relationship between corporate governance and firm performance.

The study attempts to give an operational definition of components and sub-components of ethical behavior. The findings of this study have also contributed to the literature on ethical behavior. More importantly, the findings of this study will enable higher institutions and other organizations to be responsible for developing leaders who will embrace ethical policies in business management.

The findings of this study will add to literature from which those in the field of academia can continually refer. It will form a good basis for making management decisions and administrative policy formulations. It will consequently serve as a reference point for researchers who would wish to undertake studies on ethical behavior in Ghana.

Ultimately, the findings of the study will help improve customer satisfaction when employees are encouraged to practice good ethical behavior. The customers will effectively manage their time when transacting business with the firms. The employees of these firms will better attend to their customers when good ethical policies are implemented effectively. The enforcement of good ethical behavior will improve the work of both management and employees, which will significantly help in achieving the stated goals. Appropriate sanctions must be applied when employees engage in any form of unethical behavior. This will help serve as a deterrent to others.

\subsection{Assessment of Employee's Ethical Behavior and Firm's Performance}

There are many dimensions to measuring firm performance. Financial ratios derived from financial data are important to objectively evaluate a firm's performance. Based on the literature, accounting-based performance indicators ROA and ROE are widely used financial ratios by investors to measure firm profitability(Masa'deh 2016). Velnampy, Nimalthasan et al. (2014), used ROA and ROE as determinant financial ratios of firm performance and used EPS and dividend payout as an indicator of dividend payout policy. A statistically significant relationship between EPS and dividend payout and ROE and ROA has not been established in this study, which covers manufacturing companies between 2008 and 2012. Notwithstanding these and other servicewide reform initiatives, a writer on business ethics, (Woode 1997, Woode 2000), has made several assertions about the poor work culture of the leadership of the Ghana Civil Service when he asserts that though the object of Public Administration was to provide services that go to improve the life of society, the conduct of Ghana's Public Administration was characterized by what he calls nine "deficiencies" or "wrongs." They are: "...a displaced sense of purpose, an urban bias, an elite mentality, nepotism, distrust, paternalism, centralization, and disregard for time, and an absence of organizational loyalty".

There is also the need to commit themselves fully to acquiring these professional ethics as the bedrock for efficiency, effectiveness, loyalty to an organization, and the display of market-orientated work ethics and conduct for achieving results-oriented work output;

Businesses have realized that ethical misconduct can be very costly not only for the organization but also to society as a whole (Abiodun, Adeyemi et al. 2014). Ethical behavior has been extensively researched and proven to enhance firm performance (Cragg and Matten 2011, Wessels 2011).

Business enterprises can no longer afford to disregard business ethics. There are continuous business failures as a result of unethical practices, especially those associated with employees and top executives.

Establishing the appropriate framework for organizational culture requires that the elements and principles must go through consultations and a formal approval process to ensure general acceptability and applicability to meet the expected standards of attitudes and conduct required within the organization (Attakumah 2013). Therefore, hypothesis one was developed.

H1: Assessing the extent to which employees exhibit good ethical behavior has a positive relationship with the firm's performance. 


\subsubsection{Relationship Between Ethical behavior and Firm's Performance}

Despite the growing concern of researchers in the field of business ethics, cases of unethical practices have continued to manifest in corporate organizations. Corporate leaders engage in decisions that have resulted in a lack of trust in the organization's leadership; and inadequate commitment to the organization's goals. Ethical leadership is a clarion call to the recent credit crisis, the worst global recession since the 1930s; and the various scandals in former leading corporate business organizations. Enron, Arthur Andersen, WorldCom, Tyco, Parmalat, and HealthSouth are among many businesses in the developed countries where leaders failed ethically for a variety of reasons, which may include pressures to achieve, perform, and to "win at all costs". Top executives of corporate organizations contribute to the recent credit crisis by making fraudulent decisions that artificially inflate profits to increase compensation (Victor and Soutar 2005, O'Connell and Bligh 2009, Berenbeim 2010).

In a study conducted on the understanding of executive ethical leadership (Treviño, Brown et al. 2003), ethical leaders are thought to be receptive and open, possess traditional leadership traits such as integrity, honesty, and trustworthiness. Ethical leadership includes transactional leader behaviors such as setting ethical standards and holding followers accountable for ethical conduct. Resick, Hanges et al. (2006), identified six key attributes that characterized ethical leadership which include character and integrity; ethical awareness; community/peopleorientation; motivating; encouraging, and empowering; and managing ethical accountability. Although other studies have reported a significant correlation between EL and FP of firms, this study fails to confirm the same trend. This could be due to a variety of reasons such as peculiar characteristics of the firms studied and the influence of socio-cultural environmental factors. Another reason could be that respondents could not adequately measure or identify the features of ethical leadership, as it may be a new concept to them. Hence hypothesis two was developed.

H2: Ethical leadership as a management skill has a significant influence on the financial performance of firms.

\subsubsection{Relationship between Corruption and Firm's Performance}

Corruption exists in all branches of the Ghanaian government and non-governmental agencies. Ghana ranks 81 out of 180 countries in Transparency International's 2017 Corruption Perceptions Index (CPI) (Index 2010). Despite corruption levels in Ghana remaining low compared to other African countries, it still poses an obstacle for businesses operating or planning to invest in Ghana (Integrity 2018). Rampant corruption, weak rule of law, and an under-regulated property rights system remain significant impediments to business confidence (House 2017). Bribes and irregular payments are often exchanged in return for obtaining public utilities (House 2017, Integrity 2018) Low-level government and institutional employees have been known to ask for a "dash" (tip) in return for facilitating license and permit applications, and companies applying for licenses and permits are frequently confronted with demands for facilitation payments (Integrity 2018). Financial analysts state that the widespread corruption in the public sector that companies have to deal with has taken Ghana to the dark ages, with the country's state being described as a "man drowning and clutching at straws" (Rahman 2018). Some examples of daily corruption, such as bribery and extortion, are well known to Ghanaians. It is commonplace in Ghana that to get things done, a bribe must be offered to an official before a duty for which the official is paid can be done. Well-known corrupt activities by government officials are misappropriation of public funds such as granting of loans that obviously cannot be repaid, excessive spending on security, comfort, and image enhancement, excessive, expensive foreign trips, hiring of a superfluous number of highly paid Special Government Advisors, the acquisition of private property when it is blatantly obvious that past and current earnings do not support the acquisition of such property (Sule 2012, Kwawukume 2014). Hence hypothesis three was developed.

H3: The ability of firms to reduce corruption has a significant influence on financial performance.

\subsubsection{Relationship between Nepotism and Firm's performance}

According to the Wikipedia encyclopedia, the word "nepotism" comes from the Latin word "Nepos" meaning "nephew" and it should be appreciated that nepotism may be acceptable in some countries or societies because of socio-cultural factors. It is defined as favoring relatives or friends because of their relationship with the person dispensing favors, rather than their abilities. This always has its negative effects on the general and financial performance of firms. When managers are accused of lying, cheating, or stealing, the blame is usually placed on the individual or the firm situation. Excellent young Ghanaians are stuck in unfulfilling and boring jobs because 
they lack "Whom you know" to make real headway in their careers (Sule 2012). Most people believe that individuals make ethical choices because of individual integrity, which is true, but it is not the whole story. Commonwealth Association for Public Administration and Management (Secretariat 2003).

It has been observed that there are several reasons for the increasing use of "Whom you know" including the nature and culture of the Ghanaian society where tribalism or sectarianism force people to support and defend a brother or a friend whether they are unjust or aggrieved (Nyukorong 2014). Lins and Servaes (2002), further contend that corporate governance could help to align the interests of individuals, corporations, and society through a fundamental ethical basis and it will fulfill the long-term strategic goal of the owners, building shareholder value and establishing a dominant market share. Hence Hypothesis four was developed.

H4: The elimination of nepotism in firms increases the chances for improved financial performance.

\section{Methodology}

This study followed a quantitative study design and sought to understand the magnitude to which employees' adherence to the ethics of their organizations affects the performance of their organizations. A cross-sectional study was carried out to gather data once from a relevant and appropriately sampled group of respondents from selected firms. A multi-stage sampling technique was adopted at two different levels (firm selection and respondent selection). Firms were firstly selected based on convenience by proximity and resource availability for data collection. The respondents from selected firms were randomly selected from stratified firm divisions such as management, secretariat, security, marketing, finance, etc., ensuring that each division was represented. Cross-sectional data were collected from employees of firms through the administration of structured questionnaires. A total of thirty (30) firms were selected for this study. Data were collected cross-sectional through the administration of Business Ethics and Corporate Growth Questionnaire (BECGQ) with some modifications to include only study variables relevant to this study. Six hundred (600) respondents were engaged in the data collection, comprising of employees from different divisions from selected firms in Ghana. The data gathering instrument was structured and consisted of 20-item survey questions with a 5-points Likert scale [5Strongly Agree (SA), 4-Agree (A), 3-Neutral (N), 2-Disagree (D), and 1-Strongly Disagree (SD)]. Questionnaires were administered in face-to-face mode.

\subsubsection{Model Specification and Variables.}

The multivariate regression model involving four independent variables and one dependent variable is explained in the econometric model, which is described using the following equation:

$$
y_{\mathrm{i}}=\beta_{0}+\beta_{1} x_{\mathrm{i} 1}+\beta_{2} x_{\mathrm{i} 2}+\ldots \beta_{\mathrm{p}} x_{\mathrm{ip}}+\varepsilon_{\mathrm{i}} \text { for } i=1,2, \ldots n
$$

Using real variable terms, equation 1 can be transformed into:

$$
F P=\alpha+\beta 1 G E B_{p q}+\beta 2 E L_{p q}+\beta 3 C_{p q}+\beta 4 N_{p q}+X+\varepsilon
$$

Where:

$\mathrm{FP}=$ Financial Performance $(\mathrm{ROA})$

GEB $=$ Good ethical behavior

$\mathrm{EL}=$ Ethical leadership

$\mathrm{C}=$ Corruption Reduction

$\mathrm{N}=$ Nepotism Reduction

$\mathrm{X}=$ Combination of GEB, EL, C, and N

$\varepsilon=$ Error term

$\alpha=$ Constant

$\mathrm{p}=$ represents the companies

$\mathrm{q}=$ represents the years

Variables 
The above variables shown in the econometric model will be considered in the analysis. The response variable also referred to as the dependent variable is the financial performance (FP). The predictor variables or the independent variables include good ethical behaviors (GEB), ethical leadership (EL), corruption Reduction (C), and Nepotism Reduction $(\mathrm{N})$. The dataset contains more variables such as gender, age, work division, and education level. The variation between the variables can be observed by pairing both response and predictor variables. Observations were made indicating whether the variables influence each other positively or negatively. The variables in the model are considered because they have been used to explain business financial growth and development over specified periods in the previous studies. Cross-sectional data collected were analyzed using the Statistical Package for Social Sciences (IBM-SPSS, Version 25). A multiple regression analysis was performed and statistical assessments such as correlation, and linear regression was used to establish the relationships between dependent and independent variables of the econometric model adopted for the financial performance of firms. Analysis of variance (ANOVA) was used to establish the statistical significance of model variables using a confidence interval of $99 \%$. Findings were presented in Tables and Figures.

\section{Results and Findings}

Ethics define a way of doing things and this differs from one organization to another depending on organizational culture and type of business. It is therefore important to be able to link the way employees behave to their level of satisfaction derived from their jobs and the performance of their firms.

Table 1: Cross-tabulation between the existence of ethics policy (EPE) and job satisfaction in firms

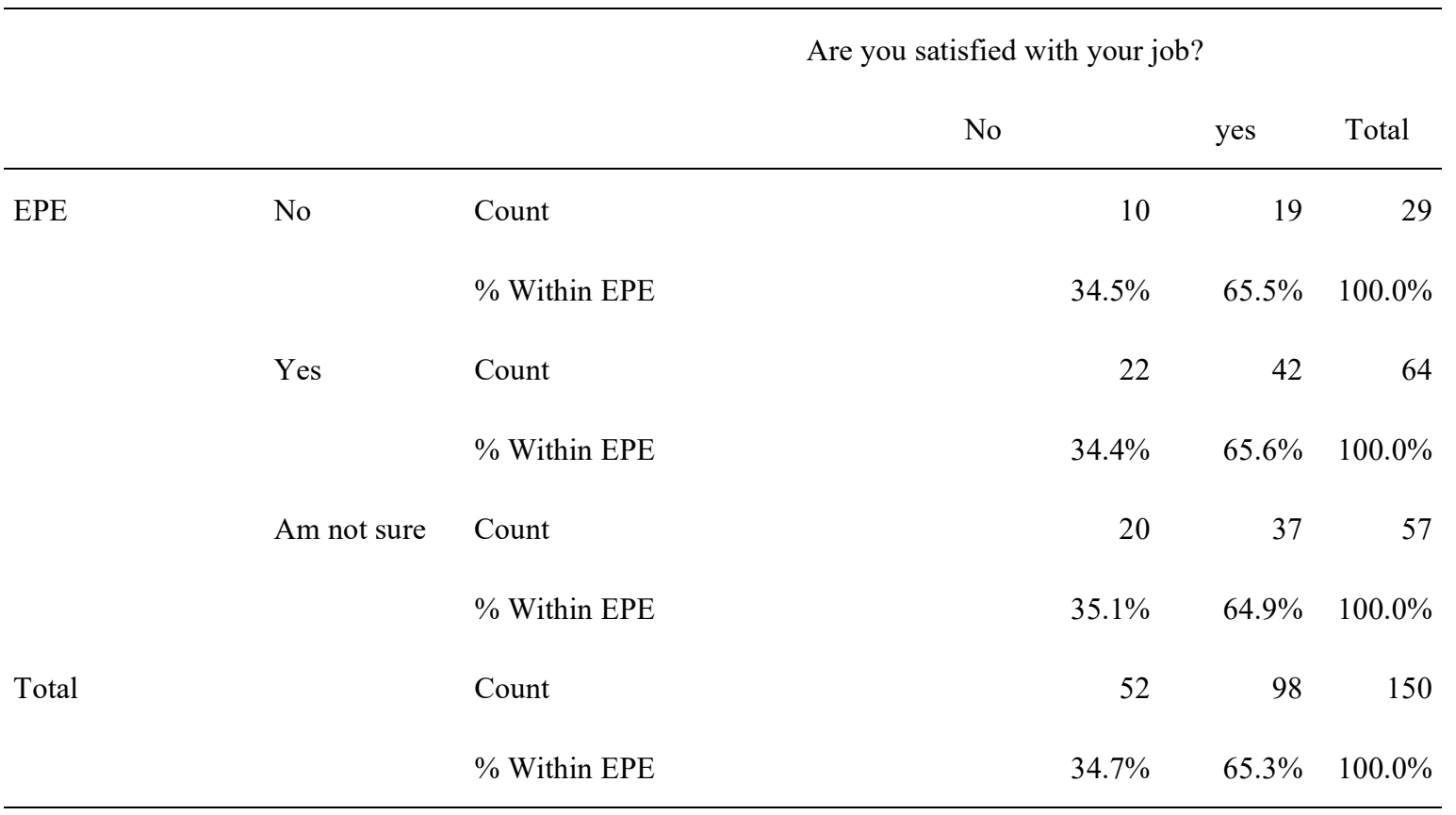

Considering the effects of the existence and implementation of ethics policies in organizations as perceived by employees (Table 1), the majority were satisfied with their jobs $(65.3 \%)$. 
Table 2: Organizational financial performance as confirmed by management staff

\begin{tabular}{|c|c|c|c|c|}
\hline & & Frequency & Percent & Cumulative Percent \\
\hline \multirow[t]{5}{*}{ Valid } & $\begin{array}{l}\text { Strongest Performance ( } \geq \\
95 \%)\end{array}$ & 17 & 48.6 & 48.6 \\
\hline & $\begin{array}{l}\text { Stronger Performance (70- } \\
94 \%)\end{array}$ & 9 & 25.7 & 74.3 \\
\hline & $\begin{array}{l}\text { Strong Performance }(50 \text { - } \\
69 \%)\end{array}$ & 5 & 14.3 & 88.6 \\
\hline & $\begin{array}{l}\text { Average Performance (30- } \\
49 \%)\end{array}$ & 2 & 5.7 & 94.3 \\
\hline & Poor Performance $(<30 \%)$ & 2 & 5.7 & 100.0 \\
\hline Total & & 35 & 100.0 & \\
\hline
\end{tabular}

Further assessment of data explored the level of organizational performance by only gathering information on financial performance as perceived by management staff who are in a better position to present facts. Financial performance levels were ranked from strongest, to stronger, to strong, to average, and to poor performance. Results indicated that $48.6 \%$ of firms performed strongest with indicators above or equal to 95 percent of set financial targets per annum (Table 2). This was followed by the stronger performance $(25.7 \%)$ satisfying between 70 to 94 percent of annual financial targets and strong performance (14.3\%) (Table 2).

Figure 1 clearly shows the different performance ranking of firms.

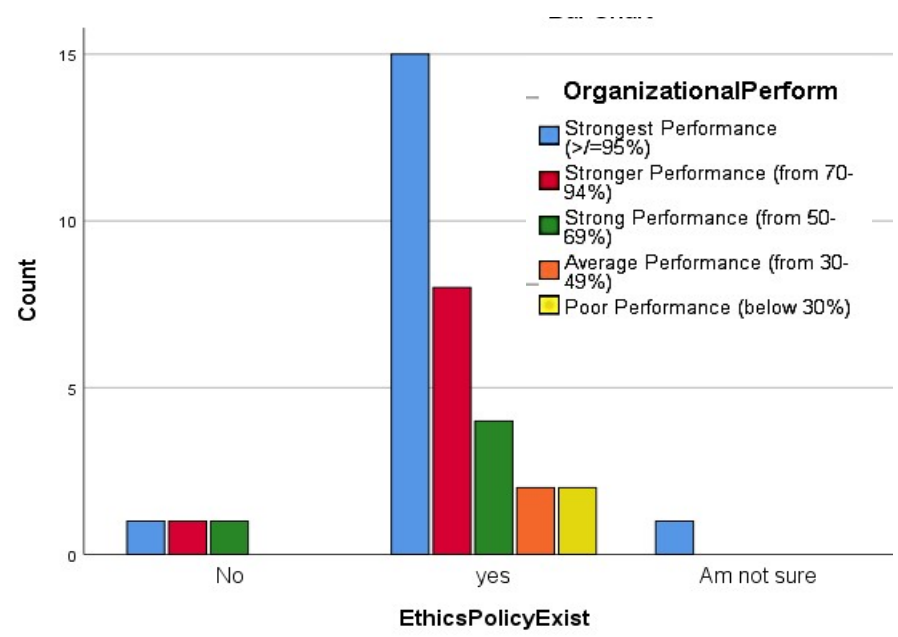

Figure 1: Financial performance of firms based on the existence of ethics policy

\section{Fit statistics of model}

The avoidance of overfitting and multicollinearity is necessary to the relevance and fitness of the model. This can be ensured by using correlations, scatter plots, and simple regressions to check for potential correlation between independent variables (multicollinearity) and to ensure that independent variables only correlate with the dependent variable. This study uses only the scatter plots and correlation analysis to check for 
multicollinearity and data fitness. Overfitting was also avoided by not including too many independent variables in the model in making predictions about the financial performance of firms.

Test for multicollinearity and fitness of data

Table 3: Correlation matrix of variables

\begin{tabular}{|c|c|c|c|c|c|c|}
\hline & & GEB & FP & EL & $\mathbf{C}$ & $\mathbf{N}$ \\
\hline \multirow[t]{3}{*}{ GEB } & Pearson Correlation & 1 & .349 & -.181 & -.050 & .003 \\
\hline & Sig. (2-tailed) & & .059 & .339 & .792 & .988 \\
\hline & $\mathrm{N}$ & 30 & 30 & 30 & 30 & 30 \\
\hline \multirow[t]{3}{*}{ FP } & Pearson Correlation & .349 & 1 & .191 & $-.503^{* *}$ & $-.680^{* *}$ \\
\hline & Sig. (2-tailed) & .059 & & .311 & .005 & .000 \\
\hline & $\mathrm{N}$ & 30 & 30 & 30 & 30 & 30 \\
\hline \multirow[t]{3}{*}{ EL } & Pearson Correlation & -.181 & .191 & 1 & .122 & .266 \\
\hline & Sig. (2-tailed) & .339 & .311 & & .521 & .156 \\
\hline & $\mathrm{N}$ & 30 & 30 & 30 & 30 & 30 \\
\hline \multirow[t]{3}{*}{ C } & Pearson Correlation & -.050 & $-.503^{* *}$ & .122 & 1 & .190 \\
\hline & Sig. (2-tailed) & .792 & .005 & .521 & & .316 \\
\hline & $\mathrm{N}$ & 30 & 30 & 30 & 30 & 30 \\
\hline \multirow[t]{3}{*}{$\mathbf{N}$} & Pearson Correlation & .003 & $-.680^{* *}$ & .266 & .190 & 1 \\
\hline & Sig. (2-tailed) & .988 & .000 & .156 & .316 & \\
\hline & $\mathrm{N}$ & 30 & 30 & 30 & 30 & 30 \\
\hline
\end{tabular}

**. Correlation is significant at the 0.01 level (2-tailed).

From Table 3, the conditions to be satisfied for the analysis of data by multiple regression are assessed. Firstly, a one-to-one mapping of each independent variable to the dependent variable must show a good correlation. If this is not satisfied, the independent variable in question cannot be included in the multiple regression analysis. Secondly, there must not be a good correlation between independent variables to avoid multicollinearity. The occurrence of this means those two related variables are so close that it becomes difficult to tell which of them explains the variance in the dependent variable, FP. With this in mind, FP correlated well with $\mathrm{C}\left(r^{2}=-0.503\right)$ and $\mathrm{N}\left(r^{2}=-0.680\right)$ and weakly with GEB $\left(r^{2}=0.349\right)$. However, there was no good correlation between FP and EL $\left(r^{2}=0.191\right)$, and so EL was not included further in the analysis. Although GEB and FP were not very well correlated, outliers in data were trimmed and that was enough to maintain it. Thus, the new model equation becomes: 


$$
F P=\alpha+\beta 1 G E B_{p q}+\beta 2 C_{p q}+\beta 3 N_{p q}+X
$$

No multicollinearity was observed between independent variables.

\section{Multiple regression analysis}

Model statistics show the various diagnostics that are used to determine the adequacy of the model and its suitability for the objectives of this study.

Table 4: Model Summary

\begin{tabular}{lcrrr}
\hline Model & R & R Square Adjusted R Square & $\begin{array}{r}\text { Std. Error of the } \\
\text { Estimate }\end{array}$ \\
\hline 1 & $.884^{\mathrm{a}}$ & .781 & .756 & 1.37135 \\
\hline
\end{tabular}

a. Predictors: (Constant), RD, DC, GEB

b. Dependent Variable: FP

Table 5: ANOVA

\begin{tabular}{llccccc}
\hline Model & & Sum of Squares & df & Mean Square & F & Sig. \\
\hline & Regression & 174.231 & 3 & 58.077 & 30.882 & $.000^{\mathrm{b}}$ \\
1 & Residual & 48.895 & 26 & 1.881 & & \\
& Total & 223.126 & 29 & & \\
& & & & & \\
\hline
\end{tabular}
a. Dependent Variable: FP
b. Predictors: (Constant), N, C, GEB

Tables 4 and 5 show the model summary and the ANOVA of the regression analysis. An $\mathrm{R}^{2}$ and adjusted $\mathrm{R}^{2}$ values of 0.78 and 0.756 respectively, and a P-value of $0.000^{* *}$ show that the model was good enough for the assessment of data and to predict the variability in FP, the dependent variable. 
Table 6: Regression coefficients

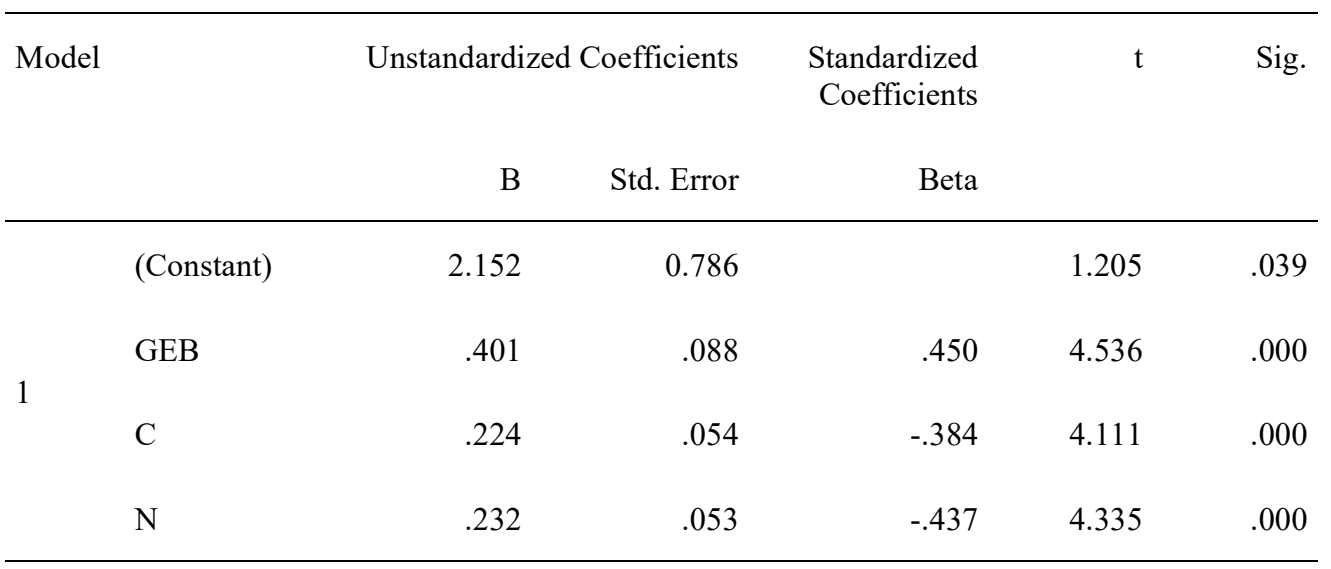

a. Dependent Variable: FP

Regression coefficients further depict the suitability of the model. All variables were highly significant at a $99 \%$ confidence interval (Table 6).

The avoidance of overfitting and multicollinearity is necessary to the relevance and fitness of the model. This can be ensured by using correlations, scatter plots, and simple regressions to check for potential correlation between independent variables (multicollinearity) and to ensure that independent variables only correlate with the dependent variable. This study uses only the scatter plots and correlation analysis to check for multicollinearity and data fitness. Overfitting was also avoided by not including too many independent variables in the model in making predictions about the financial performance of firms.

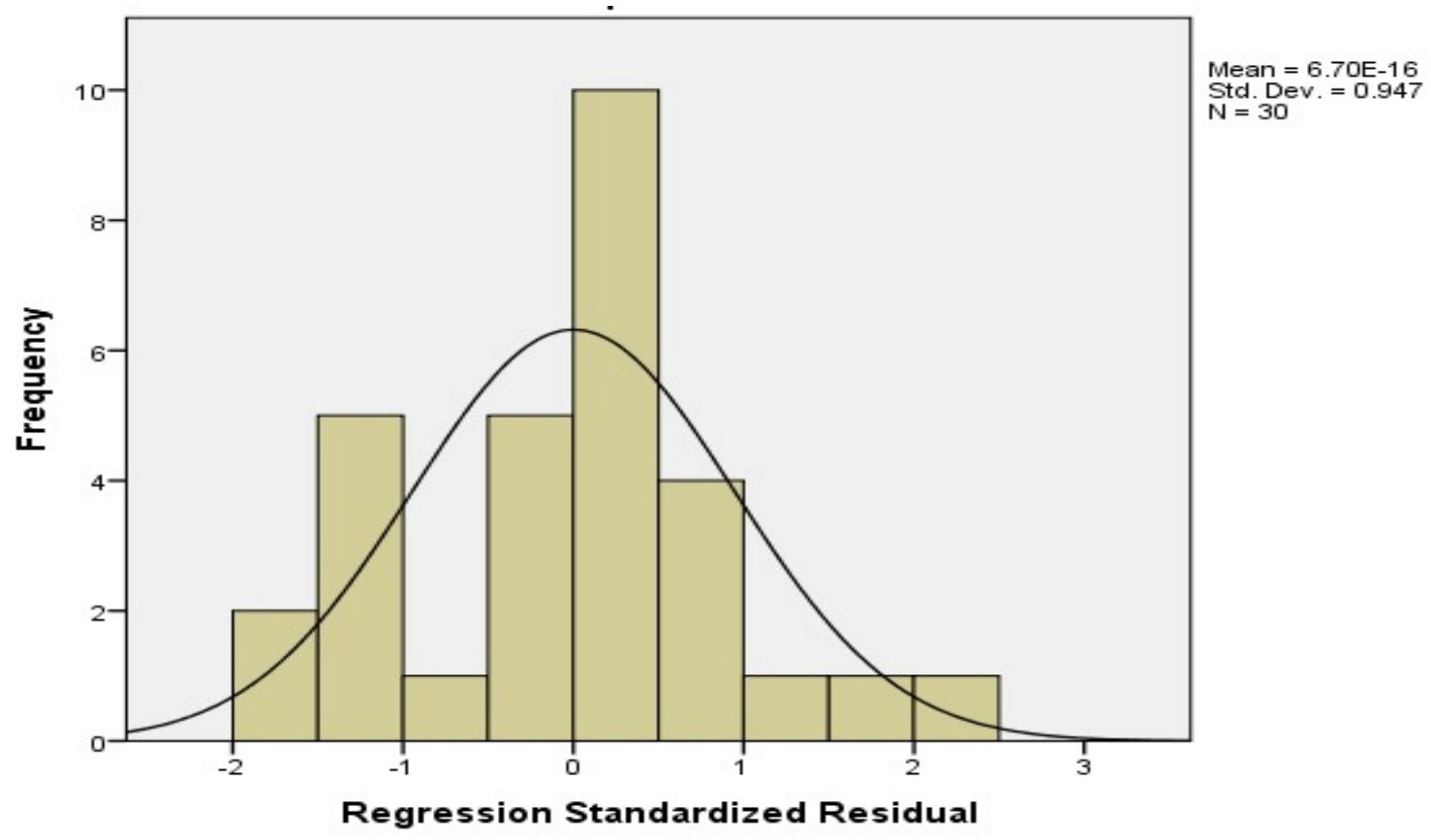

Figure 2: Histogram of standardized residuals 


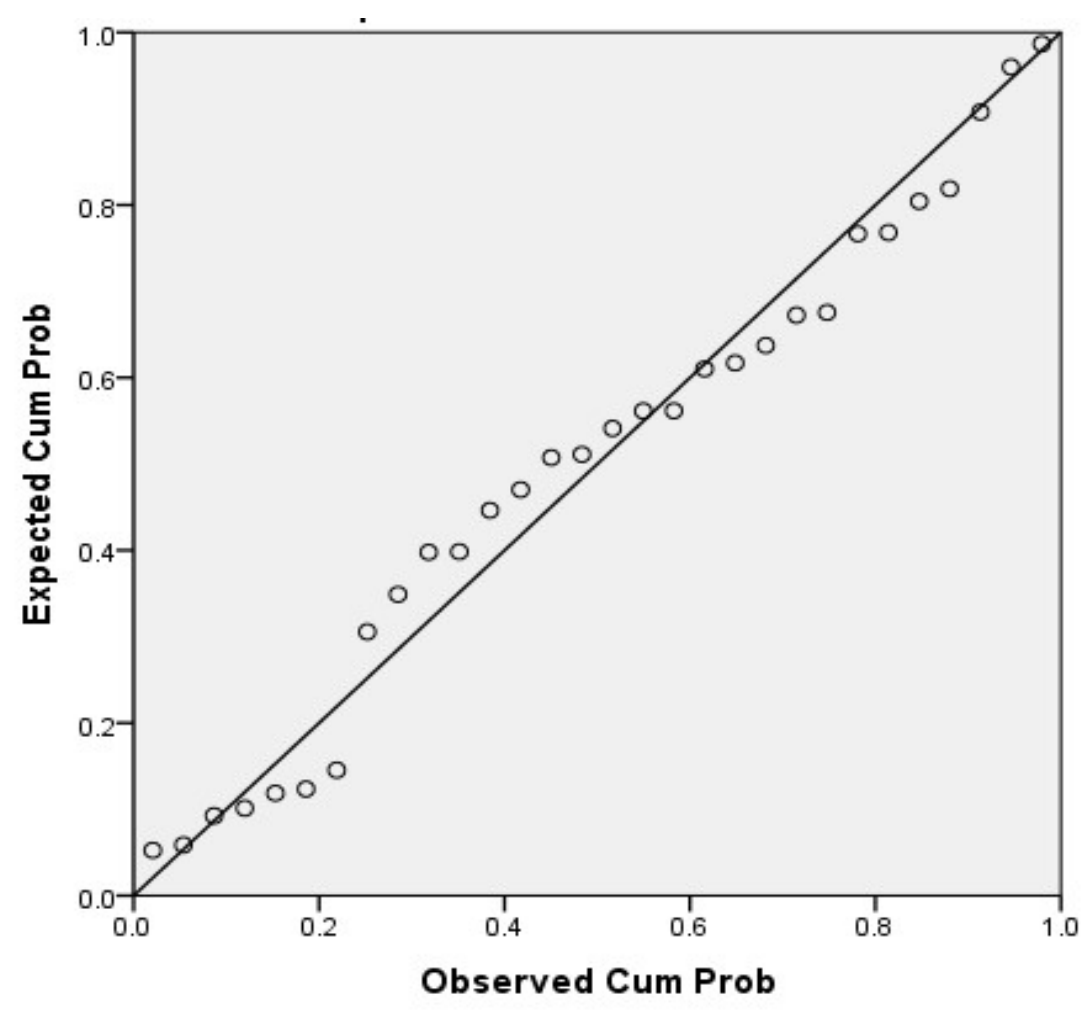

Figure 3: Standardized residual plot of variables

Standardized residual statistics show a normal distribution of data (Figure 3) for the variables studied and confirm that the model was fit for predicting the variability in a firm's financial performance based on changes in independent variables. Residual plots also show the strong statistical fitness of the model.

From regression analysis results, the regression model equation which best suits the purpose of this study was:

$$
F P=2.152+0.45 G E B_{p q^{-}} 0.384 C_{p q}-0.437 N_{p q}+1.271
$$

An increase in GEB will cause an increase in FP by 0.45 . Thus, for instance, an increase in scores for GEB of firms of 30 [maximum scale], will transform the model equation to $\boldsymbol{F B}=\mathbf{2 . 1 5 2}+\mathbf{0 . 4 5}(\mathbf{3 0})$ concerning GEB, holding all other variables constant. Thus, firms' performance will increase by 13.4 million cedis when their score for GEB is maximum, giving a total FB value of 15.552 million cedis. A similar explanation goes for variables $\mathrm{C}$ and $\mathrm{N}$.

From regression coefficients, it was observed that GEB had the highest influence on the financial performance of firms studied as it had the highest value.

\section{Discussion}

Data analysis is a very important aspect of scientific research since it breaks down data into simple and more visually appealing illustrations. Since the econometric model considered is significant, it implies that all the causative factors of the financial performance should be considered to promote the growth of the different organizations over different fiscal years.

Results from multiple regression analyses have indicated that good ethical behavior (GEB), corruption Reduction (C), nepotism Reduction $(\mathrm{N})$ have a positive influence on a firm's financial performance. Thus, there is no doubt that a firm's adherence to ethical principles positively influences its financial performance, confirming what is already available in the literature. This also supports the hypothesis of this study, that firm's financial performance will be directly related to its financial performance (Valdiserri and Wilson 2010). Any 
noted increase in any of the independent variables of the model was able to produce an increase in the performance of firms studied, except ethical leadership which failed to significantly influence the financial performance of firms in this study. This is confirmed by the fact that all correlation coefficients and model coefficients are positively related to financial performance. Such positive association assumes that improved financial performance of firms can be induced by following ethical principles, and this becomes a competitive advantage to firms as it can ensure that operations of the firm are done more efficiently, and improvements are enhanced in productivity (Cragg and Matten 2011).

Concerning corruption, this study finds that reducing corruption helps firms to increase their profit margins significantly. However, this general finding, as backed by many others is just because corruption is often seen as an evil in the business world, instead of sometimes being seen as a necessary evil (Bouvain, Baumann et al. 2013). Certain times, bribing, as an example of corrupt behavior in corporate firms is a means of making way for better opportunities for firms in conducting business (Boukou 2017). According to Boukou (2017), an empirical study using a recent dataset provided by the World Bank Enterprise Survey conducted in 2011-2013 showed that firms that perceive the court system to be corrupted and firms that perceive it to be non-corrupted both achieve growth in firm performance. This implies that corruption does not contribute negatively to a firm's growth at all. Moreover, it is suggested that the issue of corruption should be defined and assessed in the context of culture and industrial characteristics to better understand its dynamism and effect on business.

Adhering to ethical standards of business also has the potential to lower costs of compliance to policy directives and ensures that new market opportunities are properly utilized. The fact that the impact of organizational ethical behavior on financial performance can also be focused on the tension between the explicit costs of the firm and the implicit costs of other agents makes the case for adherence to ethics even more important (Weshah, Dahiyat et al. 2012). Thus, if a firm reduces its implicit costs by not offending public policies and regulations, reducing corruption and ethnic discrimination, it becomes an advantage to aid the improvement of the firm's financial performance (Valdiserri and Wilson 2010, Wessels 2011). From other perspectives, other studies have also linked organizational ethical behavior to its brand and image, which in effect influences customer relations and profits (Bouvain, Baumann et al. 2013).

Although ethical leadership has been found to have a significant influence on organizational performance in other studies (Butt, Butt et al. 2016), this study found it unrelated per the data collected as well as the extent to which the fitness of measurement procedure allowed statistically. This could be due to a variety of reasons such as peculiar characteristics of the firms studied and the influence of socio-cultural environmental factors (Ameer and Othman 2012). Another reason could be that respondents could not adequately measure or identify the features of ethical leadership, as it may be a new concept to them.

Results have shown in this study that predictor variables of the study explained the variability in the financial performance of firms with GEB, C, and N contributing up to $45 \%, 38.4 \%$, and $43.7 \%$ respectively. Thus, firms' ability to increase their scores with regards to these independent variables is proportional to the respective percentage increases predicted. Therefore, all the hypotheses except that regarding ethical leadership have been confirmed by results from this study.

\section{Conclusion and Recommendation}

In conclusion, this study explored the effects of organizational ethics on the financial performance of firms in Ghana. The method adopted was quantitative and it followed a cross-sectional survey of companies registered on the Ghanaian stock market. The return on assets (ROA) of these companies was used as an indicator of their financial performance. Being the response variable or the dependent variable of the study, good ethical behavior (GEB), corruption reduction (C) index, nepotism reduction $(\mathrm{N})$, and ethical leadership (EL) were the predictor or independent variables which explained the variabilities in the financial performance of firms studied. However, due to model fit statistics, ethical leadership was not further included in the analysis of data, although it was theoretically related strongly to the financial performance of firms.

It was recommended that training of staff, government support, and strict enforcement of the Public Officer Ethics Act (2003) be duly implemented to curb employee ethical misconduct. This will also enhance improved knowledge on ethics of conducting business as part of the policy implementation will include training or sensitization. On firms' financial performance, the ROA of firms, according to findings is positively and strongly correlated to their adherence to ethical business standards. It is therefore recommended in this study that corporate firms avoid or reduce corruption, enhance good ethical behavior through the implementation of ethics policies, and reduce or eradicate nepotism to increase their chances of performing better financially. In addition, 
firms should ensure gender equality and equity, employee training on ethical standards of work, and encouragement of ethical leadership.

Results from multiple regression analysis have indicated that good ethical behavior (GEB), corruption reduction (C), nepotism reduction $(\mathrm{N})$ have a positive influence on a firm's financial performance. Thus, there is no doubt that a firm's adherence to ethical principles positively influences its financial performance, confirming what is already available in the literature.

The social and economic situation in today's Ghana determines opportunities for and this is the intensive development of nepotism. The acceptable level of trust of the formal body and the level of interpersonal credibility in Ghana is very low, which certainly leads to the well-being of various unofficial institutions and thus corruption at all levels of governance. This research shows that nepotism often creates opportunities for the simulation of superior positions and even the whole departments for close relatives, which inevitably brings organizational effectiveness. This research concludes that further promotion of favoritism and nepotism leads to a "brain drain" from Ghana, which endangers the social and economic development of the country as a whole.

Some limitations can be improved on this study for future research. Firstly, there is the likelihood of omitted variables in the study. The study mainly looked at some key factors of ethical behavior. Perhaps, the existence of omitted ethical characteristics variables could lead to better prediction and explain a firm's financial performance well.

Secondly, the use of Return on Assets (ROA) as a proxy for financial performance has its limitations. The findings may be challenged with the use of other methods or other financial indicators as a measurement to obtain a better result.

In addition to the above, content analysis also has some drawbacks. The choice of variables to measure is subjective. Also, content analysis is only an indication of what firms say they are doing, and this may be very different from what they are doing. At best, one certainly could postulate that firms that are aware of these issues are those that will discuss them as well as act on them.

It has been observed that most of the employees were in one way or the other related to the management, hence the management does not apply the code of ethics as deemed which affects the financial performance of the firms. How can a firm's growth entire politically neutral and professionally oriented ethical policies constitute a basis for future research?

A challenge for academic researchers is to search for mechanisms to demonstrate the real effects of such practices on the firms and society as a whole. Future research should illustrate, empirically where feasible, the damaging effects of modern-day nepotism, particularly as firms grow in complexity and scale and become vulnerable to the ever-increasing competitive pressures. In extending this current study, further research work could be carried out in other sectors within the Ghanaian society, particularly in government ministries and departments. This could be a learning point for Ghana and other developing nations struggling to combat unethical behaviors in the firm's performance.

\section{References}

Abiodun, A. J., K. S. Adeyemi and A. O. Osibanjo (2014). "Quality Dimensions, Value, Service Cost and Recommendation Behaviour: Evidence from the Nigerian Cellular Industry." International Journal of Economic Behavior 4(1): 139-150.

Alem, Y., H. Eggert, M. G. Kocher and R. D. Ruhinduka (2018). "Why (field) experiments on unethical behavior are important: Comparing stated and revealed behavior." Journal of Economic Behavior \& Organization 156: 71-85.

Ameer, R. and R. Othman (2012). "Sustainability practices and corporate financial performance: A study based on the top global corporations." Journal of business ethics 108(1): 61-79.

Amos, D. N. (2012). "Business ethics: A catalyst for rapid economic growth." Journal of Educational and Social Research 2(10): 30-30.

Asare-Bediako, K. (2002). "Professional skills in human resource management." Accra. Kasbed Ltd.

Attakumah, S.-L. (2013). Relevance of the Code Conduct and Work Ethics to the Ghana Civil Service, University of Ghana.

Bandura, A. (1986). "Social foundations of thought and action." Englewood Cliffs, NJ 1986(23-28). 
Beck, S. and J. Andrews (1989). "Phase transition behavior observed in small silicon cluster ions." The Journal of chemical physics 91(7): 4420-4421.

Berenbeim, R. E. (2010). "Utilizing HR and ethics and compliance collaboration to promote an ethical culture." Employment Relations Today 37(1): 17-26.

Boukou, J. (2017). "Corruption and firm performance: An empirical study on the impact of bribe payments on the performance of Chinese firms."

Bouvain, P., C. Baumann and E. Lundmark (2013). "Corporate social responsibility in financial services: A comparison of Chinese and East Asian banks vis-à-vis American banks." International Journal of Bank Marketing.

Butt, A., A. Butt and M. Ayaz (2016). "Impact of ethical leadership on organizational performance and mediating role of corporate social responsibility: Evidence from banking sector of Pakistan." International Journal of Management Sciences and Business Research 5(6).

Cohen, T. R. (2010). "Moral emotions and unethical bargaining: The differential effects of empathy and perspective taking in deterring deceitful negotiation." Journal of Business Ethics 94(4): 569-579.

Cragg, W. and D. Matten (2011). "Ethics, corporations, and governance." Journal of business ethics 102(1): 1-4.

Dimitriou, C. K. and J. P. Ducette (2018). "An analysis of the key determinants of hotel employees' ethical behavior." Journal of Hospitality and Tourism Management 34: 66-74.

Enofe, A., P. Omagbon and F. Ehigiator (2015). "Forensic audit and corporate fraud." International Journal of Economics and Business Management 1(7): 1-10.

Gibbs, J. C. (2019). Moral development and reality: Beyond the theories of Kohlberg, Hoffman, and Haidt, Oxford University Press.

House, F. (2017). "Freedom in the World 2017-Ghana."

ICAG (2009). THE CHARTERED ACCOUNTANTS BILL. Ghana Institute of Chartered Accountants Ghana

Index, C. P. (2010). "Transparency international." URL: http://www. transparency. org/news/feature/cpi_2013_now_is_the_time_for_action.

Integrity, G. (2018). Ghana Corruption Report.

Jensen, M. C. (2010). "Value maximization, stakeholder theory, and the corporate objective function." Journal of applied corporate finance 22(1): 32-42.

Kim, M., A. C. H. Kim, J. I. Newman, G. R. Ferris and P. L. Perrewé (2019). "The antecedents and consequences of positive organizational behavior: The role of psychological capital for promoting employee well-being in sport organizations." Sport Management Review 22(1): 108-125.

Koc, M. and M. F. Çavuş (2014). "Human resource management practices, job satisfaction and organizational commitment."

Kumari, G. and K. Pandey (2011). "Analysis of an Individual's Behaviour in Work Environment For A Better Output." International Journal of Innovation, Management and Technology 2(2): 156.

Kwawukume, V. (2014). Corruption situation at tipping point, CJ. Graphic Newspaper.

Lau, P. Y. Y., J. L. T. Tong, B. Y.-H. Lien, Y.-C. Hsu and C. L. Chong (2017). "Ethical work climate, employee commitment and proactive customer service performance: Test of the mediating effects of organizational politics." Journal of Retailing and Consumer Services 35: 20-26.

Levine, M. P. and J. Boaks (2014). "What does ethics have to do with leadership?" Journal of Business Ethics 124(2): 225-242.

Lewin, K. (1951). Behavior and Development as a Function of the Total Situation In: Field theory in the social sciences: Selected theoretical papers, Harper, New York.

Lins, K. V. and H. Servaes (2002). "Is corporate diversification beneficial in emerging markets?" Financial Management: 5-31.

Masa'deh, R. e. (2016). "The role of knowledge management infrastructure in enhancing job satisfaction at Aqaba five star hotels in Jordan."

Naiyananont, P. and T. Smuthranond (2017). "Relationships between ethical climate, political behavior, ethical leadership, and job satisfaction of operational officers in a wholesale company, Bangkok Metropolitan region." Kasetsart Journal of Social Sciences 38(3): 345-351.

$\mathrm{Ng}$, T. W. and D. C. Feldman (2015). "Ethical leadership: meta-analytic evidence of criterion-related and incremental validity." Journal of Applied Psychology 100(3): 948.

Nyukorong, R. (2014). "Corruption, nepotism or the "whom you know" factor and how it affects recruitment in the banking sector of Ghana." Developing Country Studies 4(24): 38-54.

O'Connell, W. and M. Bligh (2009). "Emerging from ethical scandal: Can corruption really have a happy ending?" Leadership 5(2): 213-235. 
Onyema, E. O. (2014). "Assessing the relationship between human resource management and employee job satisfaction: A case study of a food and beverage company." Journal of Business Administration Research 3(1): 71.

Pučetaitè, R. (2014). "Stimulating organizational innovativeness through ethical leadership practices: the mediating role of organizational trust." Procedia-Social and Behavioral Sciences 156: 231-235.

Rahman, K. (2018). Overview of corruption and anti-corruption in Ghana, JSTOR.

Resick, C. J., P. J. Hanges, M. W. Dickson and J. K. Mitchelson (2006). "A cross-cultural examination of the endorsement of ethical leadership." Journal of Business Ethics 63(4): 345-359.

Schein, E. H. (2010). Organizational culture and leadership, John Wiley \& Sons.

Secretariat, C. (2003). Commonwealth Public Administration Reform 2004, Commonwealth Secretariat.

Sennewald, C. and C. Baillie (2016). "Planning and Budgeting." Effective security management.(págs. 151-164). Butterwort-Heinemann.

Seuntjens, T. G., M. Zeelenberg, N. van de Ven and S. M. Breugelmans (2019). "Greedy bastards: Testing the relationship between wanting more and unethical behavior." Personality and Individual Differences 138: $147-156$.

Sule, F. E. (2012). Effects of credit risk and portfolio loan management on profitability of microfinance banks in Lagos, Nigeria, Stellenbosch: Stellenbosch University.

Treviño, L. K., M. Brown and L. P. Hartman (2003). "A qualitative investigation of perceived executive ethical leadership: Perceptions from inside and outside the executive suite." Human relations 56(1): 5-37.

Turnley, W. H., M. C. Bolino, S. W. Lester and J. M. Bloodgood (2003). "The impact of psychological contract fulfillment on the performance of in-role and organizational citizenship behaviors." Journal of management 29(2): 187-206.

Valdiserri, G. A. and J. L. Wilson (2010). "The study of leadership in small business organizations: Impact on profitability and organizational success." The Entrepreneurial Executive 15: 47.

Valentine, S. R. and C. R. Bateman (2011). "The impact of ethical ideologies, moral intensity, and social context on sales-based ethical reasoning." Journal of Business Ethics 102(1): 155-168.

Velnampy, T., M. P. Nimalthasan and M. K. Kalaiarasi (2014). "Dividend policy and firm performance: Evidence from the manufacturing companies listed on the Colombo stock exchange." Global Journal of Management and Business Research.

Victor, G. Y. S. and G. N. Soutar (2005). The Role Of Ethical Behaviours In The Relations Between Leadership Styles And Job Performance, Australia: University of Western Australia.

Wagel, W. H. (1987). "Leadership Training for a New Way of Managing." Personnel 64(12): 4-8.

Weshah, S. R., A. A. Dahiyat, M. R. A. Awwad and E. S. Hajjat (2012). "The impact of adopting corporate social responsibility on corporate financial performance: Evidence from Jordanian banks." Interdisciplinary Journal of Contemporary Research in Business 4(5): 34-44.

Wessels, W. (2011). The European Council, Palgrave Macmillan.

Woode, S. (2000). "Ethics in Business and Public Administration." Introductory Essays and Cases, Accra. Woode, S. N. (1997). Values, Standards, and Practices in Ghanaian Organisational Life, Asempa Publishers.

Zhao, H., Q. Zhou, P. He and C. Jiang (2019). "How and when does socially responsible HRM affect employees' organizational citizenship behaviors toward the environment?" Journal of Business Ethics: 1-15. 